
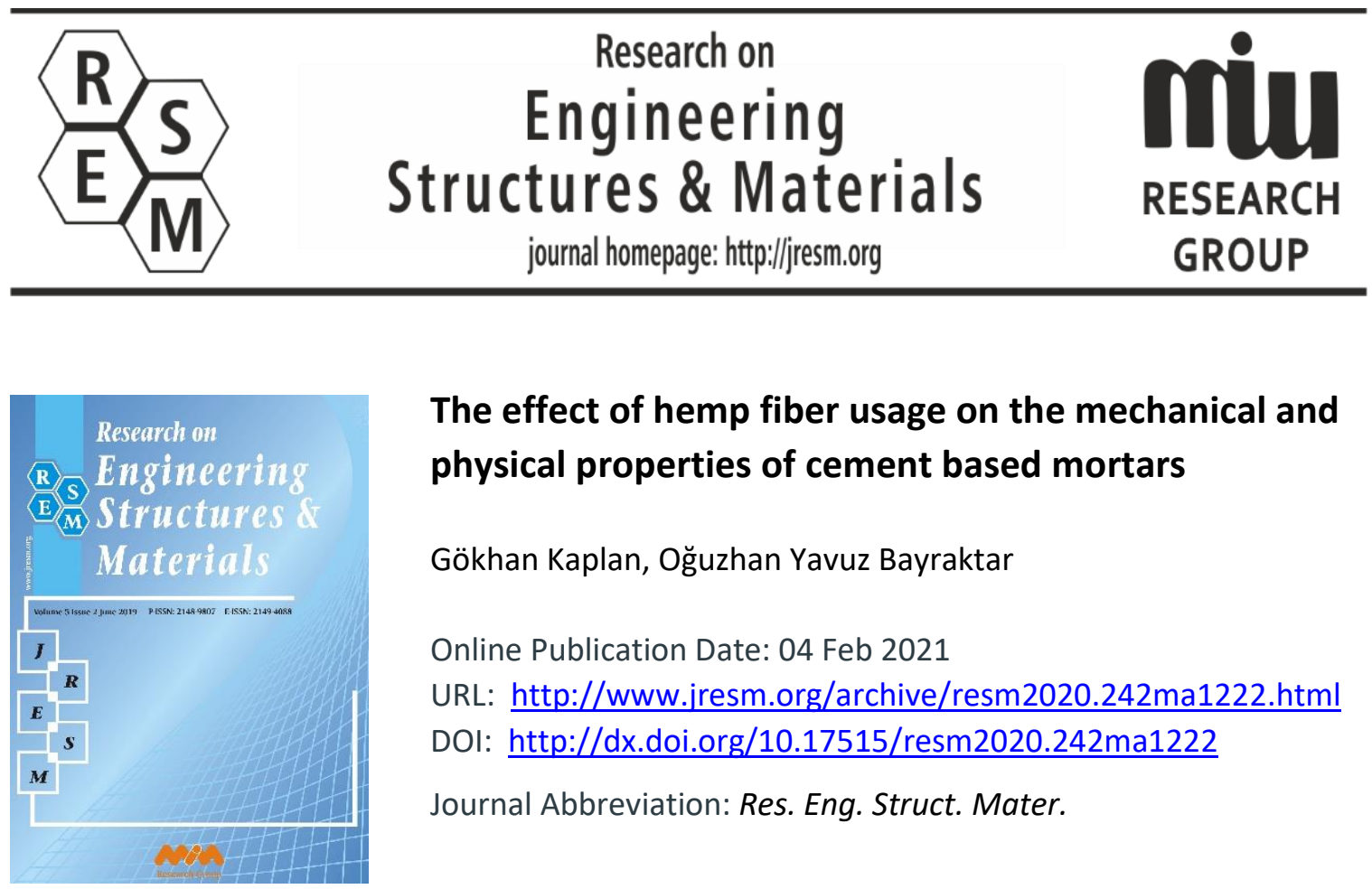

\title{
The effect of hemp fiber usage on the mechanical and physical properties of cement based mortars
}

\author{
Gökhan Kaplan, Oğuzhan Yavuz Bayraktar
}

Online Publication Date: 04 Feb 2021

URL: http://www.jresm.org/archive/resm2020.242ma1222.html

DOI: http://dx.doi.org/10.17515/resm2020.242ma1222

Journal Abbreviation: Res. Eng. Struct. Mater.

\section{To cite this article}

Kaplan G, Bayraktar OY. The effect of hemp fiber usage on the mechanical and physical properties of cement based mortars. Res. Eng. Struct. Mater., 2021; 7(2): 245-258.

\section{Disclaimer}

All the opinions and statements expressed in the papers are on the responsibility of author(s) and are not to be regarded as those of the journal of Research on Engineering Structures and Materials (RESM) organization or related parties. The publishers make no warranty, explicit or implied, or make any representation with respect to the contents of any article will be complete or accurate or up to date. The accuracy of any instructions, equations, or other information should be independently verified. The publisher and related parties shall not be liable for any loss, actions, claims, proceedings, demand or costs or damages whatsoever or howsoever caused arising directly or indirectly in connection with use of the information given in the journal or related means.

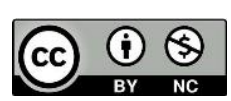

Published articles are freely available to users under the terms of Creative Commons Attribution - NonCommercial 4.0 International Public License, as currently displayed at here (the "CC BY - NC"). 


\title{
Research on Engineering Structures \& Materials
}

journal homepage: http://jresm.org

\section{The effect of hemp fiber usage on the mechanical and physical properties of cement based mortars}

\begin{abstract}
Gökhan Kaplan*1,a, Oğuzhan Yavuz Bayraktar²,b
${ }^{1}$ Atatürk University, Faculty of Engineering, Department of Civil Engineering, Erzurum, Turkey.

${ }^{2}$ Kastamonu University, Faculty of Engineering and Architecture, Department of Civil Engineering, Kastamonu, Turkey

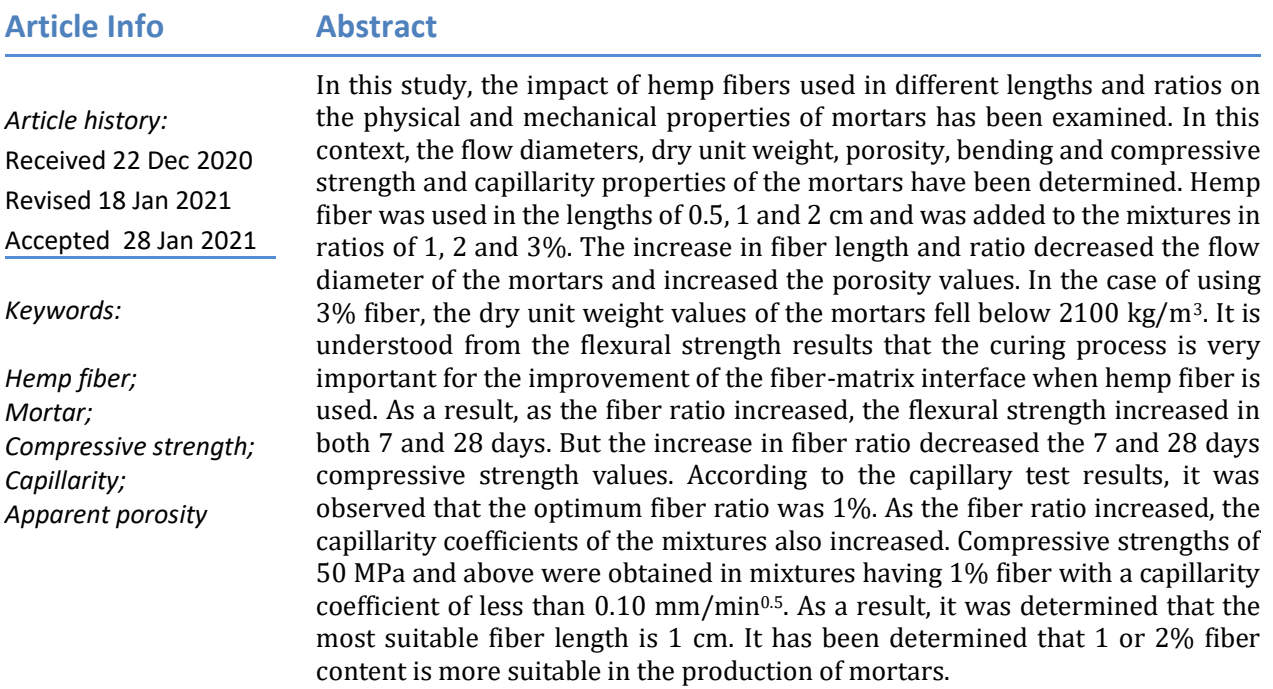

(c) 2021 MIM Research Group. All rights reserved.

\section{Introduction}

Nowadays, concrete ranks at the top among building materials that are mostly used in the world. Concrete is a brittle building material with very low tensile strength, energy absorption capacity and flexural toughness [1]. In order to eliminate this disadvantage of concrete, steel or synthetic fibers are added into it. [1]. Extensive research continues today to evaluate and determine the advantages of fiber-reinforced concrete. Various fiber types such as steel, carbon, glass, polypropylene, polyolefin are used in concrete production. The use of steel or synthetic fiber is expensive and environmentally harmful with respect to production [1]. For this reason, researches have been made in relation to the use of natural fibers in concrete production in recent years. Use of natural fiber goes back to about 5,000 years ago. Asbestos fibers have been used to strengthen clay pots in Scandinavia. In addition, the Egyptians added straw fiber into the clay blocks used in the construction of the walls [2]. Natural fibers are mostly preferred in developing countries. Since natural fibers are not fully accepted as an alternative to synthetic fibers, the use of natural fibers in developed countries is still limited. Another disadvantage of natural fibers is that their long-term durability properties are not known exactly. [3]. Natural fibers absorb more water than synthetic fibers and its distribution in concrete can sometimes create a

\footnotetext{
${ }^{*}$ Corresponding author: gkaplan@atauni.edu.tr

a orcid.org/0000-0001-6067-7337; borcid.org/0000-0003-0578-6965

DOI: http://dx.doi.org/10.17515/resm2020.242ma1222
}

Res. Eng. Struct. Mat. Vol. 7 Iss. 2 (2021) 245-258 
problem. [1]. Unlike steel or synthetic fibers, natural cellulosic fibers contribute to a more sustainable structure. The environmental impact of natural fibers is less $\mathrm{CO}_{2}$ emissions as they can be grown locally and require a low amount of energy for production. Besides, it is thought that natural fibers have negative carbon feature due to the photosynthesis of plants [1]. Mehta and Monteiro stated that natural fibers increase the tensile strength and bending toughness. [2]. It has also been observed that natural fibers improve the thermal insulation properties of concrete by reducing the thermal conductivity coefficient [4]. There are studies showing that natural fibers reduce the compressive strength because they cause adherence problems due to their superficial properties [5]. Hemp fibers, which are among natural fibers, have recently been used in the production of cement-based composites. Natural fibers must have appropriate physical and mechanical properties to be used in concrete. [6].

Usage of vegetable fibers such as hemp in terms of cost and performance was largely developed in Europe in the early 1990s and adopted by North American automakers in the late 1990s. [7]. Among the most important properties of hemp fiber, low cost and high tensile strength come to the forefront [6-8]. Hemp fibers vary in cylindrical and $\mathrm{l} / \mathrm{d}$ (length/diameter) and they often have irregular surfaces. Average tensile strength of hemp fibers is $857 \mathrm{MPa}$, and E-Modulus is approximately $58 \mathrm{GPa}$ [9]. In the study conducted by Sedan et al, E-Modulus decreased while flexural strength increased in optimum hemp fiber content. But, adherence of the fibers with the matrix was increased with the surface improvement realized with alkalis [10]. In the study they conducted, Elfordy et al improved mechanical and thermal properties of concrete blocks with hemp fiber in their study [11]. Ghalieh et al have obtained promising results regarding the use of polymer blends that are produced from hemp fiber for reinforcing reinforced concrete columns $[4,12]$. Siriluk et al. investigated the use of hemp fiber in the reinforcement phase of reinforced concrete beams. As a conclusion, they stated that it is more appropriate to apply hemp fiber to the beam in U shape (bottom surface+two side surfaces) [13]. Çomak et al showed that optimum ratio for hemp fiber with $12 \mathrm{~mm}$ length is $2-3 \%$ [14]. Ghosn et al used hemp fibers in concrete production and they observed improvements in bending toughness of concrete [15]. In the literature, there are studies [16-19] examining the contribution of hemp fiber to durability. Kremensas et al examined thermal and insulation properties of hemp fiber [20]. Besides, the microstructure properties of hemp fiber were also examined. [21-22].

In this study, physical and mechanical properties of mortars being produced from hemp fibers having different lengths and proportions have been investigated. In this regard, fresh and hardened mortar experiments have been carried out using 0.5, 1 and $2 \mathrm{~cm}$ long hemp fibers with ratios of 1,2 and $3 \%$.

\section{Material and Method}

\subsection{Materials}

CEM I 42.5R type cement being in accordance with TS EN 196-1 standard has been used in the preparation of the mixtures. Chemical and physical properties of cement are shown in Table 1. 
Table 1. Chemical and physical properties of CEM I 42,5 R

\begin{tabular}{cccccccccr}
\hline $\begin{array}{l}\text { Oxide } \\
(\%)\end{array}$ & $\mathrm{CaO}$ & $\mathrm{SiO}_{2}$ & $\mathrm{Al}_{2} \mathrm{O}_{3}$ & $\mathrm{Fe}_{2} \mathrm{O}_{3}$ & $\mathrm{MgO}$ & $\mathrm{SO}_{3}$ & $\mathrm{Na}_{2} \mathrm{O}$ & $\mathrm{K}_{2} \mathrm{O}$ & $\mathrm{LOI}$ \\
\hline $\begin{array}{l}\text { Specific } \\
\text { gravity }\end{array}$ & \multirow{3}{*}{$3,13,03$} & 4,15 & 3,56 & 1,04 & 3,01 & 0,45 & 0,71 & 3,55 \\
\hline
\end{tabular}

Limestone (limestone) having 0-4 $\mathrm{mm}$ sieve opening has been used as aggregate. Grain distribution of aggregate is shown in Figure 1. Specific gravity of aggregate has been determined to be 2.66 and the water absorption value has been determined as $2.6 \%$. Chemical and physical properties of hemp fiber are given in Table 2.

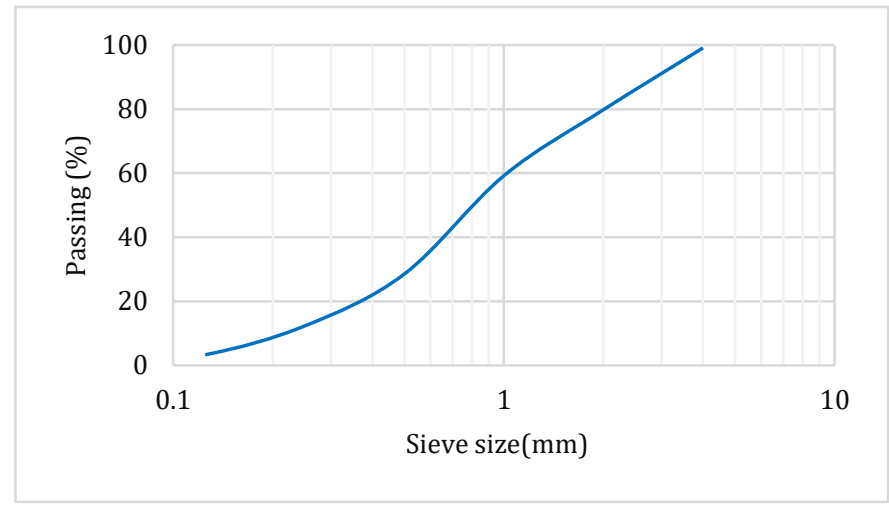

Fig.1 Particle distribution of limestone aggregate

Table 2. Technical properties of hemp fiber

\begin{tabular}{cccc}
\hline \multicolumn{2}{c}{ Chemical properties } & \multicolumn{2}{c}{ Physical properties } \\
\hline Cellulose (\%) & $70-75$ & Specific gravity & 1.47 \\
Lignin (\%) & $3.5-6.0$ & Fiber length (cm) & $0.5-2.0$ \\
Hemicellulose (\%) & $18-23$ & Moisture absorption (\%) & $\sim 12$ \\
Pectin (\%) & $4-8$ & Tensile strength (MPa) & 690 \\
Wax (\%) & 1 & Elongation at break (\%) & 3 \\
\hline
\end{tabular}

No water reducing additives have been used in preparation of the mixtures and only potable water (Kastamonu city water) has been used. Hemp fibers were used in the lengths of $0.5,1$ and $2 \mathrm{~cm}$. General view of hemp fibers is shown in Figure 2. 


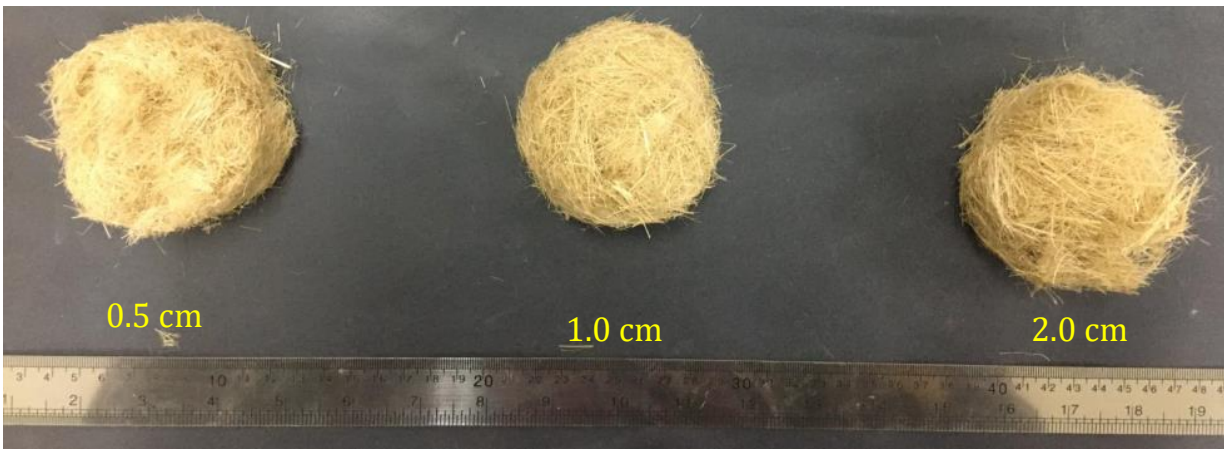

Fig. 2 General view of hemp fibers

\subsection{Method}

In the preparation of the mixtures, $\mathrm{w} / \mathrm{c}$ (water/cement) ratio was selected as 0.50 , while $\mathrm{a} / \mathrm{c}$ (aggregate/cement) ratio was selected as 3 . Amount of hemp fibers has been selected according to the cement amount. Fibers have been added to the mixture at the ratios of 1 , 2 and $3 \%$ of the cement weight. Ratios and material quantities of mixtures have been presented in Table 3. Fibers have been added to the mixture in three different lengths and ratios. A total of 10 mixtures have been prepared, including 9 different fiber mixtures and 1 non-fiber mixture (reference). Hemp fibers were latest added to the mixture. After the aggregate, water and cement were mixed homogeneously, the fibers were added to the mixture. The fibrous mixture is mixed at a low speed of 1 minute and at a high speed of 1 minute.

Table 3. Mixing ratios and material quantities

\begin{tabular}{ccccccc}
\hline & Mixing ratio & \multicolumn{4}{c}{ Material quantities (g) } \\
\hline Mix No. & Fiber length (cm) & Fiber raito (\%) & Cement & Aggregate & Water & Fiber \\
\hline 1 & 0.5 & & 450 & 1350 & 225 & 4,5 \\
2 & 1,0 & 1 & 450 & 1350 & 225 & 4,5 \\
3 & 2,0 & & 450 & 1350 & 225 & 4,5 \\
4 & 0.5 & & 450 & 1350 & 225 & 9,0 \\
5 & 1,0 & 2 & 450 & 1350 & 225 & 9,0 \\
6 & 2,0 & & 450 & 1350 & 225 & 9,0 \\
7 & 0.5 & & 450 & 1350 & 225 & 13,5 \\
8 & 1,0 & 3 & 450 & 1350 & 225 & 13,5 \\
9 & 2,0 & & 450 & 1350 & 225 & 13,5 \\
10 (Ref.) & - & - & 450 & 1350 & 225 & - \\
\hline
\end{tabular}

Flow diameters on the mortars have been determined first in accordance with the ASTM C 1437 standard. Mortars have been placed in the molds in two layers by applying vibration. Compressive and flexural strengths of 7 and 28 days have been carried out in accordance with ASTM C 349 and ASTM C 348 standards. For flexural strength test, prism samples of $40 \times 40 \times 160 \mathrm{~mm}$ have been used and compressive strength test has been carried out on the samples being divided into two at the end of the test. Capillarity properties of mortars have been determined in samples of 50x50x50 mm and in accordance with ASTM C 1585 
standard. At the end of 28 days of curing, samples have been dried at $50{ }^{\circ} \mathrm{C}$ for 3 days and capillarity test was started. After water impermeability material has been applied to side surfaces of the samples, amount of water being absorbed by capillary way at 1 th, 5 th, 10 th, 20th, 30th, 60th, 120th, 180th, 240th, 300th, 360th and 1440th minutes has been determined. Water absorption and porosity properties have been determined according to Archimedes' principle. Cube samples having size of 50x50x50 mm were used in relation to water absorption and porosity properties.

\section{Results and Discussion}

\subsection{Fresh mortar properties}

As a result of the experiment being performed according to ASTM C 1437 standard, the fresh state properties of some mortars (mixtures sufficient and poor in terms of workability) are shown in Figure 3. Flow diameters of mortars are shown in Figure 4.
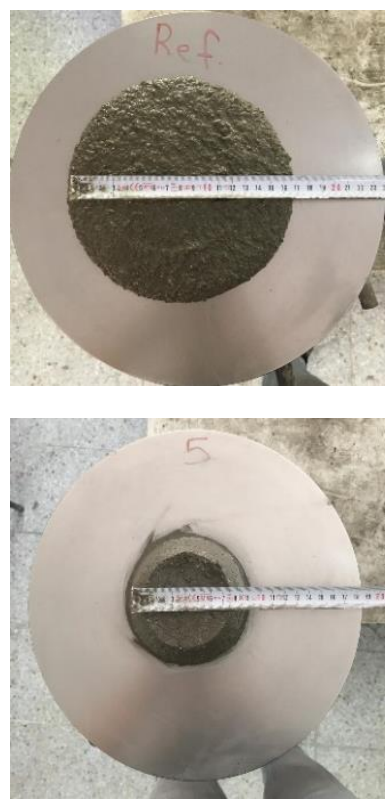
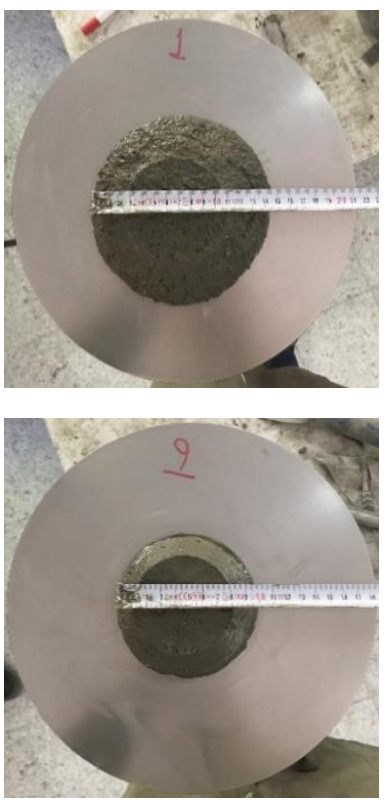

Fig. 3 Fresh properties of some mortars

As it is seen in Figure 4, as the fiber ratio and length increase, flow diameters of mortars get reduced. Flow diameters of mortars vary in the range of 14.4-9.4 cm. While the diffusion diameter of the reference mixture without fibers has been determined as 16.8 $\mathrm{cm}$, the flow diameters of the mixtures with the addition of fiber has decreased below 15 $\mathrm{cm}$. Spread diameter was generally $10 \mathrm{~cm}$ or below, especially when the fiber ratio was 2 or $3 \%$. As a result of the increase in fiber length, the maximum processability loss has occurred at the ratio of $1 \%$ fiber. If the fiber length increased from $0.5 \mathrm{~cm}$ to $2 \mathrm{~cm}$, flow diameter decreased by $29.8 \%$. In the mixtures with $3 \%$ fiber, this ratio has been determined as $5 \%$. Flow diameters of mixtures in which fiber with ratio of 2 and $3 \%$ has been used, showed similar properties. Usage of $2 \mathrm{~cm}$ long or $3 \%$ fiber affected the workability of the mortars negatively. Flow diameters of the fiber mixtures decreased by an average of $40 \%$ compared to the reference mixture. 
As a result of the increase in fiber content and ratio, workability properties of mortars decrease. As a result of the increase in the fiber ratio, internal friction increases, hence decreasing the processability. If the fiber length increases, the fibers are not distributed homogeneously in the mixture and in this case it decreases the processability [23]. Similar results were observed in other studies in the literature [24-26].

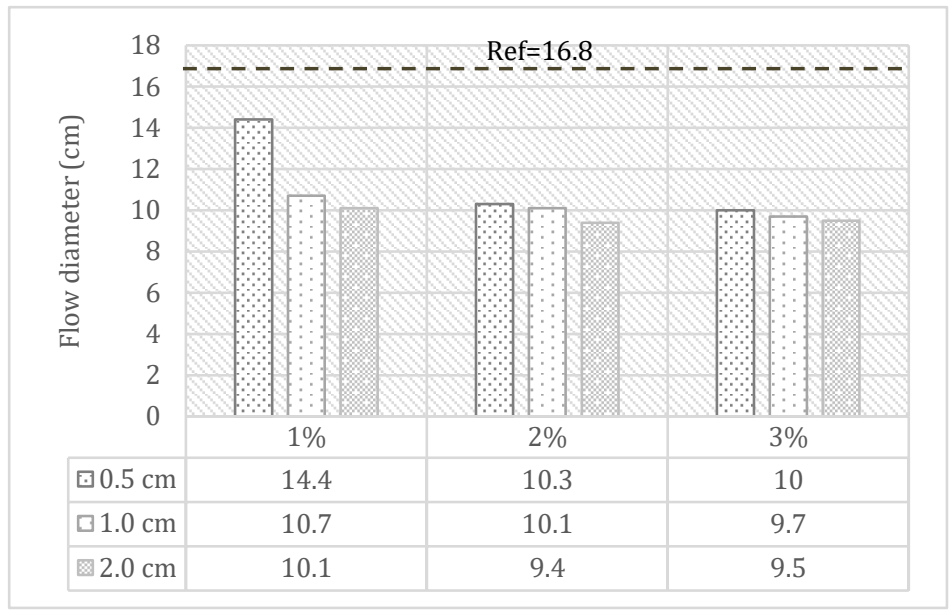

Fig. 4 Flow diameters of mortars with different fiber ratios and lengths

\subsection{Dry Bulk Density (BD) and porosity properties of mortars}

BD and visible porosity of the mortars are presented in Figure 5. BD values of fibrous mixtures vary in the range of $2037-2251 \mathrm{~kg} / \mathrm{m}^{3}$ (Figure $5 \mathrm{a}$ ). BD value of the reference mixture without fiber is determined as $2116 \mathrm{~kg} / \mathrm{m}^{3}$. BD of the mixtures using only $3 \%$ fiber were lower than the reference mixture. This situation can be explained by the loss of workability. If 1 and 2\% fiber is used, BD values are higher than the reference. When 1 and $2 \%$ fiber mixtures have been compared, the increase in fiber ratio increased the BD values of mortars. Reason for this effect can be explained by the particular that the mixing ratios are not volume-based and the proportions are fixed. Because as a result of the increase in the amount of fiber, BD values have increased. At 3\% fiber content, the difficult placement of the mortars in the mold caused the formation of a hollow structure. When the fiber length is 1 or $2 \mathrm{~cm}$, the BD values of mortars generally decrease. BD value exceeded 2250 $\mathrm{kg} / \mathrm{m}^{3}$ in the case of only $2 \%$ and $2 \mathrm{~cm}$ long fiber. Mixtures with a flow diameter of $10 \mathrm{~cm}$ and less, using 3\% fiber, also have BD values below $2100 \mathrm{~kg} / \mathrm{m}^{3}$. Since the increase in fiber length prevents homogeneous distribution, it decreased the processability and as a result, the BD values generally decreased.

In Figure $5 b$, it is seen that the porosity values of fiber-based mixtures vary between 7.38$10.18 \%$. As the fiber ratio in the mixtures increases, the apparent porosity values also increase. In addition, the increase in fiber length increased the apparent porosity values. Values closest to $7.88 \%$, which is the porosity value of the reference mixture, were obtained in mixtures in which $1 \%$ fiber was used. Even the use of 0.5 and $1 \mathrm{~cm}$ long fibers made the porosity values come below the reference mixture. Mixtures produced from 0.5 $\mathrm{cm}$ long fibers were more homogeneous than other mixtures, as the spread diameter was $14.4 \mathrm{~cm}$. This situation caused a decrease in porosity values. In addition, it has been stated in some studies that short fibers reduce porosity by acting as micro aggregates. The porosity values of the mixtures using 2 and $3 \%$ fiber are above $8 \% .\left(2037 \mathrm{~kg} / \mathrm{m}^{3}\right)$ It is seen that the use of fiber with a length of $2 \mathrm{~cm}$ and $3 \%$ in mixtures provides the lowest BD value 
and the porosity value exceeds $10 \%$. In the study conducted by Olivito and Zuccarello, as the length of the steel fiber increases, the unit volume weight values decrease. However, this reduction is negligible. In addition, as the steel fiber ratio increased, the unit weight values of the mixtures increased [27]. In the study conducted by Asasutjarit et al, as the fiber length increased, the density of the composites decreased and the water absorption values increased. [28].

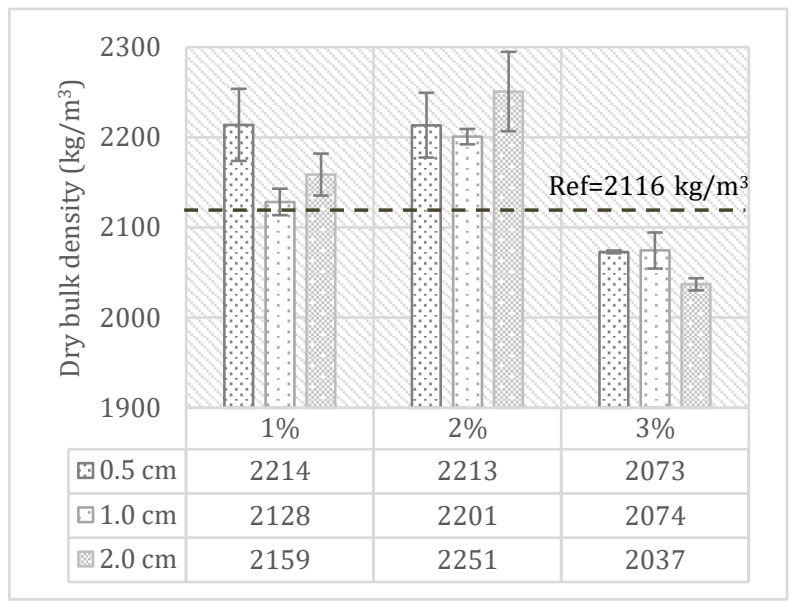

(a) Dry bulk density

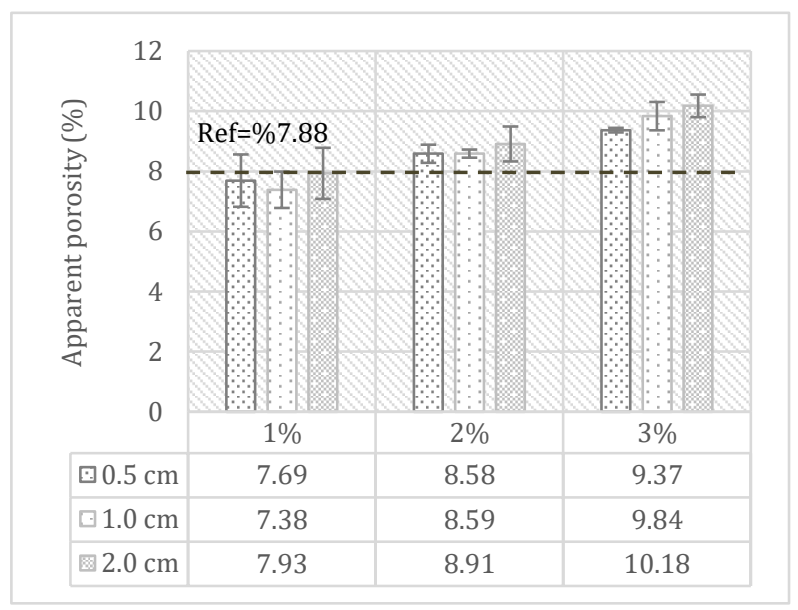

(b) Apparent porosity

Fig. 5 Physical properties of fibrous and non-fibrous mortars

\subsection{Mechanical properties of mortars}

The 7 and 28 days flexural strength results of the mortars are given in Figure 6. As seen in Figure 6, it is seen that the 7 and 28 days flexural strength of the mortars do not show parallelism. 


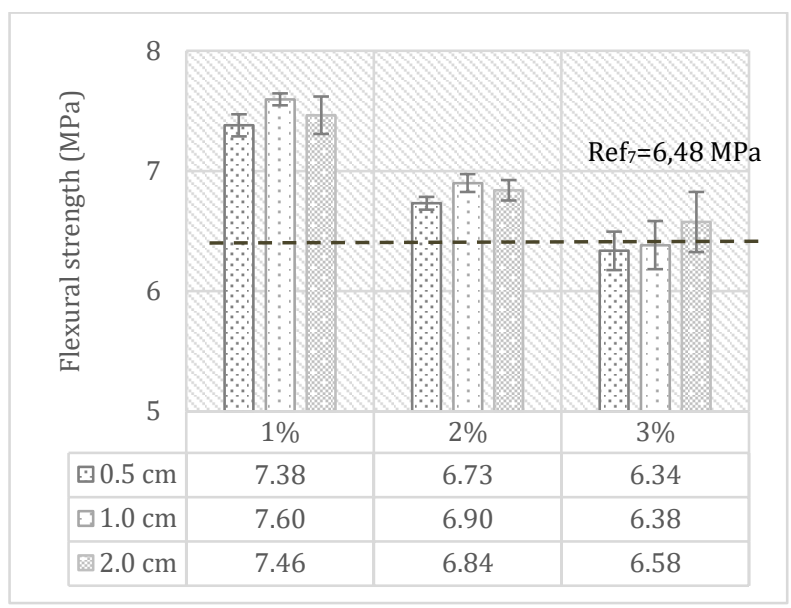

(a) 7 days

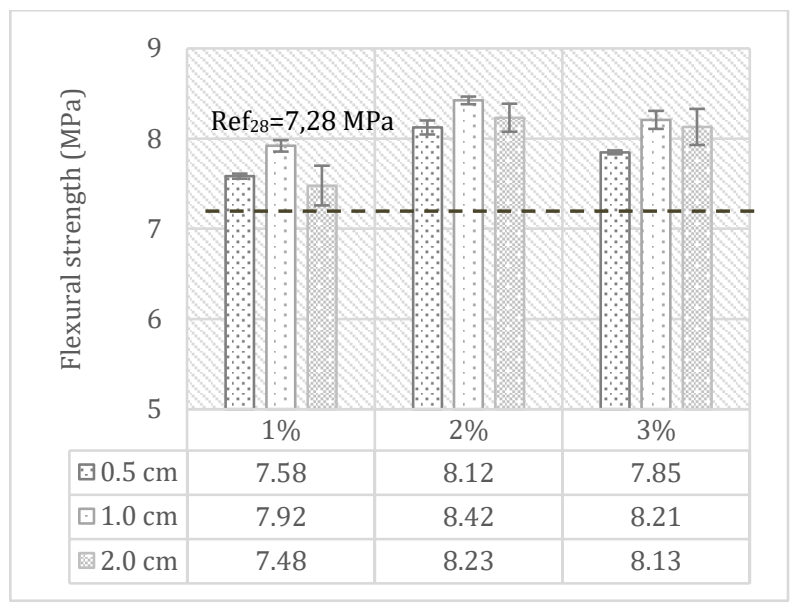

(b) 28 days

Fig. 6 Flexural strength of mortars

Figure $6 \mathrm{a}$ shows that the bending strength of the fiber-free mixture is $6.48 \mathrm{MPa}$. When using $3 \%$ of 0.5 and $1 \mathrm{~cm}$ long fibers, the flexural strength was lower than the reference. This situation is thought to be caused by the loss of workability. Fiber length of $2 \mathrm{~cm}$ relatively increased flexural strength. In general, the increase in fiber length increases the bending strength. The highest bending strength was obtained when $1 \%$ fiber of $1 \mathrm{~cm}$ length was used. Flexural strength increased by $14.7 \%$ compared to the reference mixture. As a result of the increase in fiber ratio, their bending strength decreases. In particular, the use of $3 \%$ fiber has reduced the flexural strength to less than $6.50 \mathrm{MPa}$.

Figure $6 \mathrm{~b}$ shows the 28-day flexural strength of the mortars. As a result of the increase in curing time, the flexural strength of the mortars has improved significantly. While the increase in fiber ratio in the 7-day bending strength caused a loss of strength, the opposite was observed in the 28-day blends. Especially, the strength of the mixture with a 7-day bending strength of $6.58 \mathrm{MPa}, 2 \mathrm{~cm}$ long and containing 3\% fiber, increased by $23.6 \%$ on the 28th day. On the 28th day, flexural strength of all mixtures is higher than the reference 
mixture. Up to $2 \%$ fiber ratio, as the fiber length and ratio increases, the bending strength increases. Reductions in flexural strength were observed at 3\% fiber content. It is understood that the ratio of $1 \mathrm{~cm}$ of the optimum fiber length is $2 \%$. As a result of the increase in curing time, the fiber-matrix interface improved and resulted in an increase in flexural strength. It may be necessary to keep the curing period long for natural fibers such as hemp. It would be more appropriate to examine these findings with SEM analysis. Page et al. As the hemp fiber ratio increased, the bending strength increased. The increase in fiber length decreased the bending strength [29]. In addition, it was emphasized that the consistency of the mixture is effective in fiber orientation and that in this case it affects the bending strength. [30].

As seen in Figure 7a, the highest compressive strengths were obtained at $1 \%$ fiber content. As a result of the increase in fiber ratio, their 7-day compressive strength decreased. Using $1 \%$ of the $0.5 \mathrm{~cm}$ long fiber increased the compressive strength by $4.2 \%$ compared to the reference mixture. Fiber length of $1 \mathrm{~cm}$ generally increases compressive strength. It has been observed that blends produced from 0.5 and $2 \mathrm{~cm}$ long fibers have similar properties. If the fiber content was 3\%, the compressive strength remained below the reference mixture. Figure $7 \mathrm{~b}$ shows that the compressive strength increases as a result of the increase in curing time. All blends produced with $1 \%$ fiber provided higher compressive strength than the reference blend. However, as the fiber ratio increases, the compressive strength of the mortars decreases. Compressive strength of mixtures especially produced with 3\% fiber is below $50 \mathrm{MPa}$. However, the fiber length being $1 \mathrm{~cm}$ generally increases the compressive strength. Page et al. Similar results were observed in the study conducted by [29]. Since the porosity values of the mixtures using fiber at 2 and $3 \%$ ratios are high, their compressive strength has decreased. However, an increase in bending strength was achieved at $2 \%$ fiber content. Although the porosity is high in these mixtures, the fibers act as reinforcement, preventing the crack propagation and increasing the bending strength. 


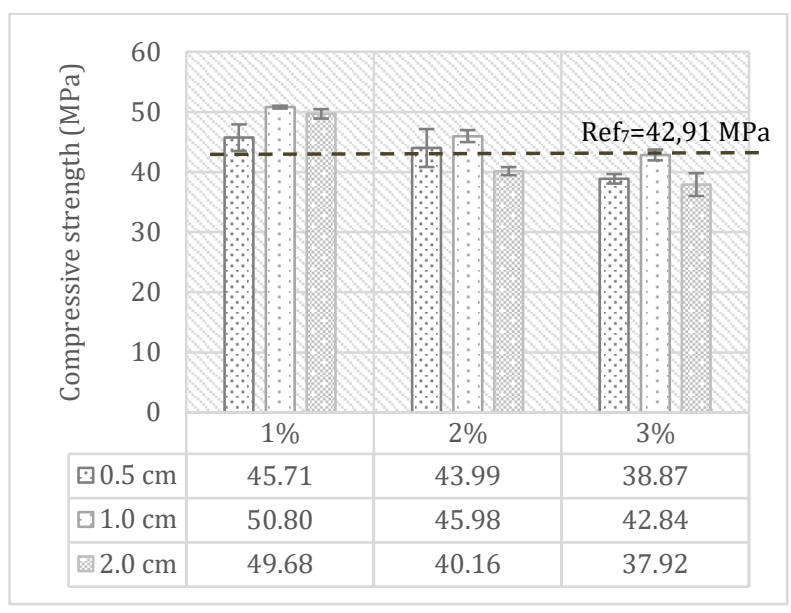

(a) 7 days

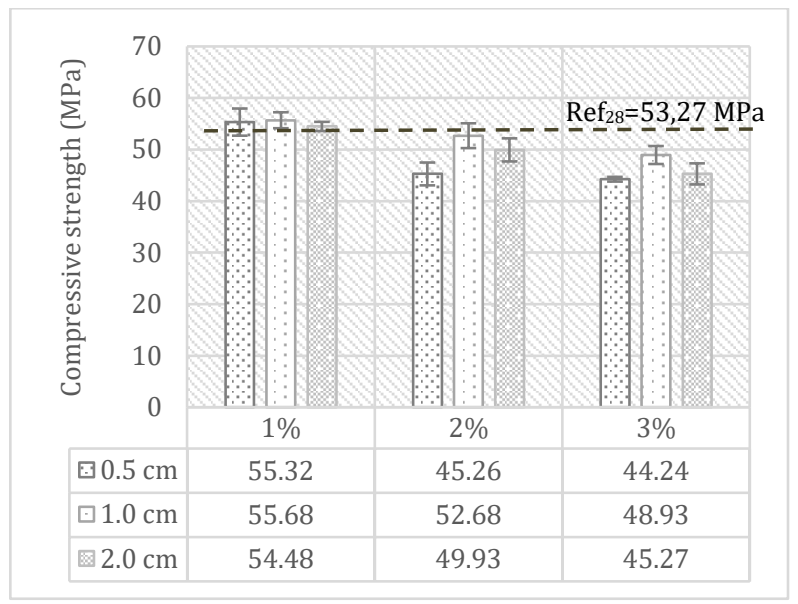

(b) 28 days

Fig. 7 Compressive strength of mortars

\subsection{Sorptivity properties of mortars}

Sorptivity properties of mortars based on time are shown in Figure 8. With the increase in the fiber ratio, capillary coefficient of mortars also increased. Besides, the use of $1 \mathrm{~cm}$ long fiber reduces the capillarity coefficient, while the situation where fiber length is $2 \mathrm{~cm}$ negatively affects this. Capillarity coefficient of the reference mixture was measured to be $0.125 \mathrm{~mm} / \mathrm{min}^{0.5}$, and mixtures with $1 \%$ fiber ratio remained below this value. It was observed that the mixtures with $2 \%$ fiber content showed values close to the reference mixture. It is seen that capillarity and compressive strength show similar properties. It was observed that mortars with low capillarity coefficient showed higher compressive strength.

Taywood has made a quality classification for capillary properties of cement-based composites [31]. Classification is graded as good if the capillarity coefficient is less than $0.10 \mathrm{~mm} / \mathrm{min}^{0.5}$, it is graded as medium if it is between $0.1-0.2 \mathrm{~mm} / \mathrm{min}^{0.5}$, and it is graded as bad if it is greater than $0.2 \mathrm{~mm} / \mathrm{min}^{0.5}$. Using $1 \%$ of fibers of 1 and $2 \mathrm{~cm}$ long fibers 
reduced the capillarity coefficient below $0.10 \mathrm{~mm} / \mathrm{min}^{0.5}$. The capillarity coefficient exceeded $0.20 \mathrm{~mm} / \mathrm{min}^{0.5}$ in the case of using $3 \%$ of $2 \mathrm{~cm}$ long fiber. It is observed that the mortars generally have a medium level of capillarity. In the study conducted by Nibudey et al, capillarity coefficient of the mixtures increased as the fiber ratio increased [32]. Similar results were found in the study conducted by Ramezanianpour et al. [33]. Rostami et al reported that fibers can also reduce the porosity of mixtures by closing gaps in some cases. [34].

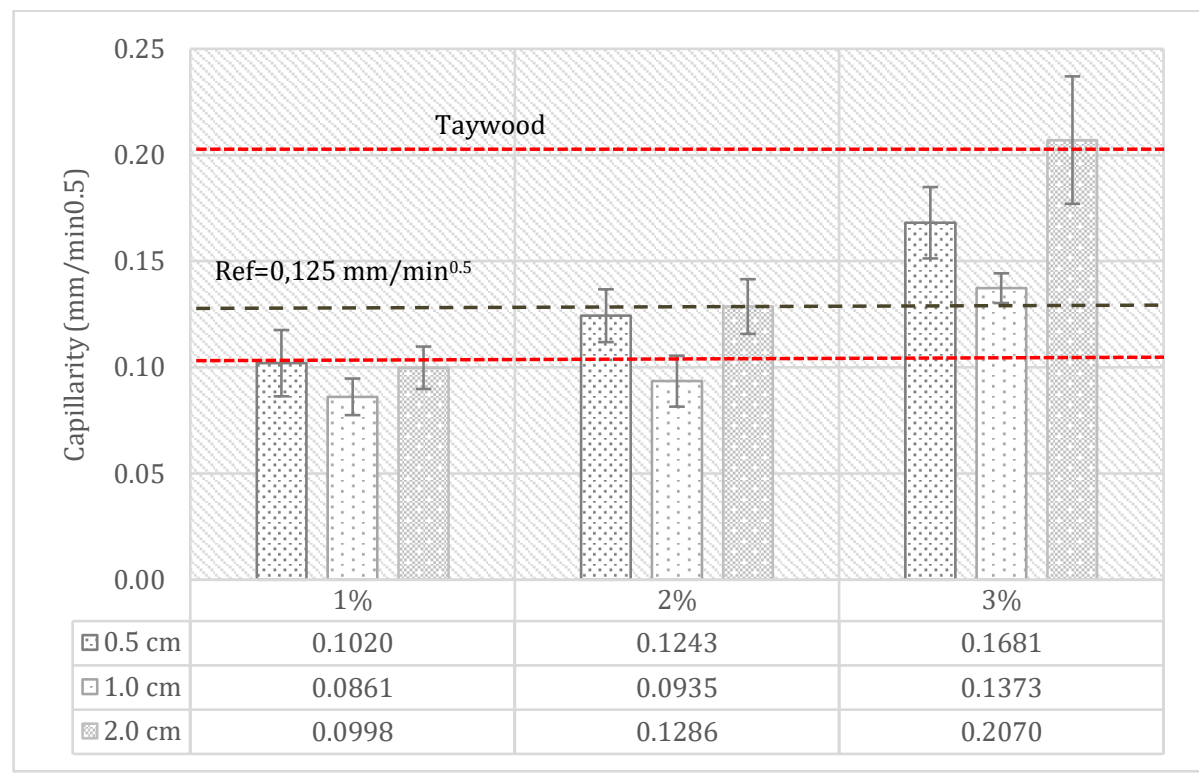

Fig. 8 Sorptivity properties of mortars

\section{Conclusions}

Increasing of fiber length and ratio has decreased the flow diameter of mortars. Especially if $3 \%$ fiber is used, flow diameters have decreased below $10 \mathrm{~cm}$. Increasing of fiber length and ratio prevents homogeneous distribution of fibers.

Using $2 \%$ fiber increased the BD values of the mixtures. But with the fiber ratio being $3 \%$, the $\mathrm{BD}$ values decreased depending on the processability. There is a difference of approximately $10 \%$ in the BD values between the mixtures. As the fiber length and ratio increase, porosity values of mixtures increase. Especially if 2 and $3 \%$ fiber was used, higher porosity value was obtained compared to the reference mixture.

As the fiber ratio increased in the 7-day mixtures, the flexural strength decreased. However, the increase in fiber length increased the flexural strength relatively. In 28-day mixtures, as the fiber ratio increased, the flexural strength increased. This is an indication of the improvement of the fiber-matrix interface with improved hydration. It has also been observed that $1 \mathrm{~cm}$ long fibers are more suitable in terms of flexural strength. 
As the fiber ratio increases in 7- and 28-day mixtures, the compressive strength decreases. If the fiber length was $1 \mathrm{~cm}$, the compressive strength increased, while the strength loss occurred at $2 \mathrm{~cm}$ fiber length. It has been observed that with $1 \%$ hemp fiber, compressive strengths of $50 \mathrm{MPa}$ and above can be obtained.

Capillarity coefficients of mixtures produced with 3\% fiber ratio were relatively higher. But the capillarity coefficients of the mixtures using $1 \%$ fiber are below $0.10 \mathrm{~mm} / \mathrm{min}^{0.5}$. Fiber length' being $2 \mathrm{~cm}$ significantly increased capillary coefficients. It was observed that the optimum fiber length in terms of capillarity is $1 \mathrm{~cm}$.

As a conclusion, it was determined that the best performance in terms of fiber length should be $1 \mathrm{~cm}$. Considering the flexural strength, it has been determined that the optimum fiber ratio should be $2 \%$.

\section{References}

[1] Zhou X, Saini H, Kastiukas G. Engineering properties of treated natural hemp fiber$\begin{array}{llll}\text { reinforced } & \text { concrete. Front } & & \end{array}$ https://doi.org/10.3389/fbuil.2017.00033

[2] Mehta PK, Monteiro PJM. Third Edition Prentice- Hall, Inc., Englewood Cliffs, NJ. Concrete: microstructure, properties, and materials. 2006.

[3] Stevulova N, Cigasova J, Estokova A, Terpakova E, Geffert A, Kacik F, et al. Properties characterization of chemically modified hemp hurds. Materials (Basel). 2014. https://doi.org/10.3390/ma7128131

[4] Ghalieh L, Awwad E, Saad G, Khatib H, Mabsout M. A Study on the Behavior of Concrete Columns Wrapped with Hemp Fabrics. Mag Concr Res. 2020 Sep;1-35. https://doi.org/10.1680/imacr.20.00103

[5] Bentur A, Mindess S. Fibre Reinforced Cementitious Composites. Fibre Reinforced Cementitious Composites. 2006. https://doi.org/10.1201/9781482267747

[6] Li Z, Wang L, Wang X. Compressive and flexural properties of hemp fiber reinforced concrete. Fibers Polym. 2004. https://doi.org/10.1007/BF02902998

[7] Ramadevi K, Deepa Shri S. Flexural behaviour of hemp fiber reinforced concrete beams. ARPN J Eng Appl Sci. 2015.

[8] Rai A, Joshi YP. Applications and Properties of Fibre Reinforced Concrete. J Eng Res Appl www.ijera.com ISSN. 2014.

[9] Pickering KL, Beckermann GW, Alam SN, Foreman NJ. Optimising industrial hemp fibre for composites. Compos Part A Appl Sci Manuf. 2007. https://doi.org/10.1016/j.compositesa.2006.02.020

[10] Sedan D, Pagnoux C, Smith A, Chotard T. Mechanical properties of hemp fibre reinforced cement: Influence of the fibre/matrix interaction. J Eur Ceram Soc. 2008; https://doi.org/10.1016/j.jeurceramsoc.2007.05.019

[11] Elfordy S, Lucas F, Tancret F, Scudeller Y, Goudet L. Mechanical and thermal properties of lime and hemp concrete ("hempcrete") manufactured by a projection process. Constr Build Mater. 2008. https://doi.org/10.1016/i.conbuildmat.2007.07.016

[12] Ghalieh L, Awwad E, Saad G, Khatib H, Mabsout M. Concrete Columns Wrapped with Hemp Fiber Reinforced Polymer - An Experimental Study. In: Procedia Engineering. 2017. https://doi.org/10.1016/j.proeng.2017.07.062

[13] Siriluk S, Hussin Q, Rattanapitikorn W, Pimanmas A. Behaviours Of RC deep beams strengthened in shear using hemp fiber reinforced polymer composites. Int J GEOMATE. 2018. https://doi.org/10.21660/2018.47.STR167

[14] Çomak B, Bideci A, Salli Bideci Ö. Effects of hemp fibers on characteristics of cement based mortar. Constr Build 2018. https://doi.org/10.1016/i.conbuildmat.2018.03.029 
[15] Ghosn S, Cherkawi N, Hamad B. Studies on Hemp and Recycled Aggregate Concrete. Int J Concr Struct Mater. 2020 Dec;14(1):54. https://doi.org/10.1186/s40069-020$\underline{00429-6}$

[16] Kalpana K, Thamizhthendral K, Dhanalakshmi G. Investigation on the Performance and Durability of Hemp Concrete. Int Res J Eng Technol. 2018.

[17] Ramadan R, Saad G, Awwad E, Khatib H, Mabsout M. Short-Term Durability of Hemp Fibers. In: Procedia Engineering. 2017. https://doi.org/10.1016/j.proeng.2017.07.018

[18] Walker R, Pavia S, Mitchell R. Mechanical properties and durability of hemp-lime concretes. Constr Build 2014. https://doi.org/10.1016/i.conbuildmat.2014.02.065

[19] Ziane S, Khelifa M-R, Mezhoud S. A Study of the Durability of Concrete Reinforced with Hemp Fibers Exposed to External Sulfatic Attack. Civ Environ Eng Reports. 2020; https://doi.org/10.2478/ceer-2020-0025

[20] Kremensas A, Stapulioniene R, Vaitkus S, Kairyte A. Investigations on Physicalmechanical Properties of Effective Thermal Insulation Materials from Fibrous Hemp. In: Procedia Engineering. 2017. https://doi.org/10.1016/j.proeng.2017.02.069

[21] Hamzaoui R, Guessasma S, Mecheri B, Eshtiaghi AM, Bennabi A. Microstructure and mechanical performance of modified mortar using hemp fibres and carbon nanotubes. Mater Des. 2014. https://doi.org/10.1016/i.matdes.2013.10.084

[22] Mostefai N, Hamzaoui R, Guessasma S, Aw A, Nouri H. Microstructure and mechanical performance of modified hemp fibre and shiv mortars: Discovering the optimal formulation. Mater Des. 2015. https://doi.org/10.1016/i.matdes.2015.06.102

[23] Kasagani H, Rao CBK. Effect of graded fibers on stress strain behaviour of Glass Fiber Reinforced Concrete in tension. Constr Build Mater. 2018. https://doi.org/10.1016/j.conbuildmat.2018.06.193

[24 Ismail MA, Hashim H Bin. Palm oil fiber concrete. 3rd ACF Int Conf -ACF/VCA. 2008.

[25] Liu G, Cheng W, Chen L. Investigating and optimizing the mix proportion of pumping wet-mix shotcrete with polypropylene fiber. Constr Build Mater. 2017. https://doi.org/10.1016/j.conbuildmat.2017.05.169

[26] Salman GA. The effect of mineral additions and adding various types, length and volume of fibers on fresh properties of self compacting concrete. In: Rheology and processing of Construction Materials - 7th RILEM International Conference on SelfCompacting Concrete and 1st RILEM International Conference on Rheology and Processing of Construction Materials. 2013.

[27] Olivito RS, Zuccarello FA. An experimental study on the tensile strength of steel fiber reinforced concrete. Compos Part B Eng. 2010. https://doi.org/10.1016/j.compositesb.2009.12.003

[28] Asasutjarit C, Hirunlabh J, Khedari J, Charoenvai S, Zeghmati B, Shin UC. Development of coconut coir-based lightweight cement board. Constr Build Mater. 2007. https://doi.org/10.1016/j.conbuildmat.2005.08.028

[29 Page J, Khadraoui F, Boutouil M, Gomina M. Multi-physical properties of a structural concrete incorporating short flax fibers. Constr Build Mater. 2017. https://doi.org/10.1016/j.conbuildmat.2017.02.124

[30] Boulekbache B, Hamrat M, Chemrouk M, Amziane S. Flowability of fibre-reinforced concrete and its effect on the mechanical properties of the material. Constr Build Mater. 2010. https://doi.org/10.1016/i.conbuildmat.2010.02.025

[31] McLeish A. Structural assessment, manual for life cycle aspects of concrete in buildings and structures. Taywood Eng Limited, UK B. 1987.

[32] Nibudey RN, Nagarnaik PB, Parbat DK, Pande AM. Compressive Strength and Sorptivity Properties of Pet Fiber Reinforced Concrete. Int J Adv Eng Technol. 2014.

[33] Ramezanianpour AA, Esmaeili M, Ghahari SA, Najafi MH. Laboratory study on the effect of polypropylene fiber on durability, and physical and mechanical characteristic 
of concrete for application in sleepers. Constr Build Mater. 2013. https://doi.org/10.1016/i.conbuildmat.2013.02.076

[34] Rostami V, Shao Y, Boyd AJ. Durability of concrete pipes subjected to combined steam and carbonation curing. Constr Build Mater. 2011. https://doi.org/10.1016/j.conbuildmat.2011.03.025 